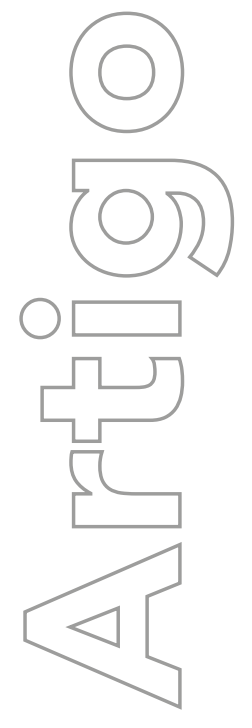

revista

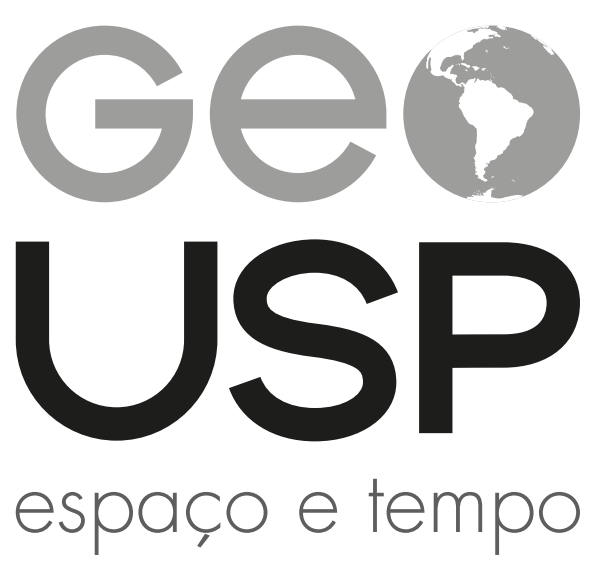

Volume $25 \cdot n^{\circ} 2(2021)$

ISSN 2179-0892

\section{Uma análise da política pública de habitação urbana no estado de São Paulo}

\author{
Angélica Vieira de Souza-Lopes \\ Universidade Estadual Paulista. Instituto de Geociências \\ e Ciências Exatas. Rio Claro. São Paulo. Brasil \\ angelicaviso@hotmail.com \\ (iD) 0000-0003-3578-5269 \\ Thiago Bueno Saab
}

Universidade Estadual Paulista. Instituto de Geociências

e Ciências Exatas. Rio Claro. São Paulo. Brasil thiagobuenosaab@hotmail.com

(D) 0000-0002-1483-225X

\section{e-173754}

Como citar este artigo:

SOUZA-LOPES, A. V.; SAAB, T. B. Uma análise da política pública de habitação urbana no estado de São Paulo. Geousp, v. 25, n. 2, e-173754, ago. 2021. ISSN 2179-0892.

Disponível em: https://www.revistas.usp.br/geousp/article/ view/173754. doi: https://doi.org/10.11606/issn.2179-0892. geousp.2021.173754.

\section{(c) (i)}

Este artigo está licenciado sob a Creative Commons Attribution 4.0 Licence 


\title{
Uma análise da política pública de habitação urbana no estado de São Paulo
}

\section{Resumo}

Considerados importantes marcos na política habitacional do estado de São Paulo, neste artigo são analisados os processos de implementação do Programa de Aceleração do Crescimento: Minha Casa Minha Vida (PAC-MCMV) e de Urbanização de Assentamentos Precários (PAC-UAP). Para tanto, se apresentam dados do histórico dos programas habitacionais brasileiros e paulistas e da política desenvolvida nesses programas específicos, além de considerações sobre o modo como as políticas públicas se efetivaram nesse estado e em sua cidade-região. Quanto ao procedimento metodológico, a partir de uma investigação descritivo-analítica, observaram-se o número de obras concluídas e o volume dos investimentos. Os resultados revelaram que, embora essas políticas públicas tenham números expressivos de habitações e estejam pulverizadas por todo o estado, há uma grande concentração desses empreendimentos na Região Administrativa de Campinas e na Região Metropolitana de São Paulo, ambas na cidade-região.

Palavras-chave: Desenvolvimento. Habitação. Programa de Aceleração do Crescimento.

\section{An analysis of public policy for urban housing in the state of São Paulo}

\begin{abstract}
Considered important milestones in the housing policy of the state of São Paulo, this article analyzes the implementation processes of the Growth Acceleration Programs: My house, My life (PAC-MCMV) and Urbanization of Precarious Settlements (PAC-UAP). To this end, data are presented on the history of the Brazilian and São Paulo housing programs and on the policy developed by the MCMV and UAP programs, in addition to considerations on how public policies were implemented in this state and in its city-region. As for the methodological
\end{abstract}


procedures, from a descriptive-analytical investigation, for the presentation of the results, the number of completed works and the volume of investments made were observed. The results revealed that, although these public policies have expressive numbers of dwellings and are scattered throughout the state, there is a great concentration of these developments in the Administrative Region of Campinas and in the Metropolitan Region of São Paulo, both inserted in the city-region.

Keywords: Development. Housing. Growth Acceleration Program.

\section{Una análisis de la política pública de vivienda urbana en el estado de São Paulo}

\section{Resumen}

Considerados hitos importantes en la política de viviendas sociales del estado de São Paulo, este artículo analiza los procesos de implementación de los Programas de "Aceleración del Crecimiento": "Mi casa, Mi vida" (PAC-MCMV) e de "Urbanización de los Asentamientos Precarios" (PAC-UAP) Para ello, se presentan datos sobre la historia de los programas habitacionales brasileños y paulistas y sobre la política desarrollada por los programas MCMV y UAP, además de consideraciones sobre cómo se implementaron las políticas públicas en ese estado y en su ciudad/región. En cuanto a los procedimientos metodológicos, a partir de una investigación descriptivo-analítica, para la presentación de los resultados se observó el número de trabajos terminados (construcción de las viviendas) y el volumen de inversiones realizadas. Los resultados revelaron que, si bien estas políticas públicas tienen números expresivos de viviendas y se encuentran dispersas por todo el estado, existe una gran concentración de estos desarrollos en la Región Administrativa de Campinas y en la Región Metropolitana de São Paulo, ambas insertas en la ciudad/región.

Palabras clave: Desarrollo. Viviendas sociales. Programa de Aceleración del Crecimiento.

\section{Introdução}

Mesmo com a mudança do papel do Estado após a crise do fordismo, passando mais à condição de regulador do que de viabilizador de projetos nacionais, algumas áreas como infraestrutura e garantia dos direitos civis à moradia, por exemplo, ficaram sob sua tutela e campo 
de ação. Destarte, no cenário desalentador do deficit habitacional brasileiro e sobretudo com o intuito de dinamizar a indústria da construção civil, criaram-se as políticas públicas de habitação.

No Brasil, a criação do Banco Nacional da Habitação (BNH), em 1964, é considerada um relevante marco para as políticas públicas de habitação. Essa iniciativa propunha a dinamização da política de captação de recursos para financiar habitações por meio das cadernetas de poupança e dos recursos do Fundo de Garantia por Tempo de Serviço (FGTS). Além do BNH, outra importante instituição que viabilizou a construção de moradias no Brasil foi o Programa de Aceleração do Crescimento (PAC), criado em 2007, cujo propósito consistia em retomar o planejamento e a execução de grandes obras de infraestrutura social, urbanística, logística e energética no país. No estado de São Paulo, os programas Minha Casa Minha Vida (MCMV) e Urbanização de Assentamentos Precários (UAP) são as principais políticas habitacionais desenvolvidas no âmbito do PAC.

Considerando, portanto, a representatividade dessas iniciativas públicas no estado mais populoso da federação, São Paulo, e visando analisar como se efetivaram as políticas públicas habitacionais nas últimas décadas, foram definidos os seguintes objetivos específicos: verificar o histórico dos programas habitacionais brasileiros e sua interlocução com a realidade paulista; compreender a política pública desenvolvida pelo PAC 1 e 2, o MCMV e a UAP; e, por fim, analisar, à luz das contribuições teóricas sobre ações de desenvolvimento regional, como as políticas públicas se efetivaram no estado de São Paulo, bem como na cidade-região, enfatizando a Região Metropolitana de São Paulo (RMSP) e a Região Administrativa de Campinas (RAC). Quanto às bases teóricas, foram tomados estudos sobre os conceitos de coesão territorial e de cidade-região, bem como informações (fonte secundária) da base de dados do PAC e do extinto Ministério das Cidades. Para entender o efeito espacial e a territorialização das políticas públicas, foram produzidos dois mapas, referentes ao PAC-MCMV e ao PAC-UAP.

\section{Programas habitacionais brasileiros}

\section{O Programa de Aceleração do Crescimento (PAC): histórico e implementação}

O PAC foi lançado oficialmente em 22 de janeiro de 2007, no primeiro mês do segundo mandato (2007-2010) do ex-presidente Luiz Inácio Lula da Silva, priorizando o investimento público em infraestrutura social e urbana, como as políticas de habitação, de saneamento e de mobilidade, e a infraestrutura econômica, como transportes, energia e comunicações, visando impulsionar o crescimento econômico, com perspectivas de ampliação da oferta de bens e serviços de natureza pública.

De acordo com Cardoso Júnior e Navarro (2016, p. 12), no plano econômico, os anos iniciais do primeiro mandato de Lula (2003-2006) foram marcados por fortes constrangimentos macroeconômicos, "[...] com o produto interno bruto (PIB) estagnado em 2003, altos patamares de juros internos, fragilidade fiscal e externa, e inflação na casa dos $9 \%$ ao ano, acima, portanto, do teto da meta estipulada pelo Banco Central do Brasil (BCB)". Do ponto de vista social, a taxa 
de desemprego em 2003 era de 12,3\%, além das elevadas taxas de desocupação e os altos níveis de informalidade, o salário-mínimo era de apenas $R \$ 388,20$ (valor referente a 2010).

Nesse contexto, a maior parte da população inserida no mercado de trabalho recebia um salário-mínimo e não tinha "[...] condições mínimas de renda para as despesas correntes de alimentação, vestuário, habitação, transporte, cultura" (Cardoso Júnior; Navarro, 2016, p. 14). Nessa ótica, o Projeto Piloto de Investimento (PPI), elaborado em 2004 e anterior ao PAC, foi uma carteira de empreendimentos de infraestrutura em diversas áreas, como abastecimento hídrico, irrigação e transporte, também em infraestrutura de pesquisa e desenvolvimento. $\bigcirc \mathrm{PPI}$ surge porque se percebe

A deterioração da infraestrutura [...] como um grande limitador do potencial de crescimento da economia. Nesse cenário, mesmo os adeptos da ortodoxia liberal passaram a admitir a necessidade da elevação dos investimentos públicos em infraestrutura, desde que os projetos passassem pela análise de custo-benefício, para mensurar a sua contribuição ao crescimento econômico. $\bigcirc$ raciocínio básico era que a despesa presente seria compensada com o fomento no crescimento futuro da economia provocado pelos projetos do PPI (Abreu; Câmara, 2015, p. 83).

Observa-se, portanto, conforme Barbosa e Souza (2010), que com o aumento do investimento público em infraestrutura também aumentou o crescimento econômico no país. Assim, o crescimento do PIB entre 2003 e 2005 foi de 3,2\%, contra 5,2\% de 2006 a 2008.

Com isso, a aceleração do crescimento foi obtida com controle da inflação e queda na taxa real de juros da economia, mesmo diante de uma elevação significativa nos preços internacionais das commodities agrícolas e minerais em 2008. Externamente, a aceleração do crescimento foi acompanhada pelo acúmulo de reservas internacionais, que reduziu a vulnerabilidade externa da economia, e pela apreciação do real, que atenuou as pressões inflacionárias externas (Barbosa; Souza, 2010, p. 14).

Nesse cenário, vale, ainda, destacar a questão do preço das commodities para a geração de divisas para o país. Segundo Rossi (2012), os mercados de algumas commodities, em geral, tornaram-se espaços viabilizadores da especulação, fazendo com que o rumo dos preços à vista acompanhe os ciclos internacionais de liquidez. Assim, observa-se que o aumento do preço das commodities acarreta num maior valor de exportações, concorrendo para um balanço superavitário, gerando divisas e beneficiando os cofres públicos.

Já no ano de 2007, com a execução do PAC, as políticas federais de investimentos em infraestruturas foram reorganizadas, centralizadas e ampliadas. "A estratégia do governo federal, pela primeira vez em muitas décadas, foi apoiar a formação de capital da parte do setor privado e, simultaneamente, aumentar o investimento público em infraestrutura" (Barbosa; Souza, 2010, p. 15). Assim, para o período de 2007-2010, na versão inicial do PAC, o investimento previsto foi de $R \$ 504$ bilhões, dividido em três grandes grupos: $R \$ 58$ bilhões para infraestrutura em 
transporte e logística, representando $11,50 \%$ do total; $\mathrm{R} \$ 275$ bilhões para infraestrutura em energia, o que equivale a 54,60\%; e $\mathrm{R} \$ 171$ bilhões para infraestrutura social, correspondendo a $33,90 \%$ do total do investimento previsto.

Conforme prosseguia a execução dos projetos de investimentos do PAC, os números e as metas eram reavaliados e estendidos nos anos seguintes. Assim, o PAC buscou aliar os investimentos em infraestrutura aos de habitação, ambos considerados "gargalos" do Brasil, que persistem como graves problemas até os dias atuais. No entanto, essa medida pode ser considerada uma política expansionista que engendrou melhorias na demanda agregada, na produção, no emprego e na renda, como se discute em seguida.

\section{Os programas habitacionais brasileiros: recuperação histórica}

Em 1964, a Lei n. 4.380 criou o Banco Nacional de Habitação (BNH), órgão central, normativo e financiador do Sistema Financeiro de Habitação (SFH), instituído com a criação do BNH. Já o Fundo de Garantia do Tempo de Serviço (FGTS) foi criado de acordo com a Lei n. 5.107/1966, dando seguimento, posteriormente, à criação do Sistema Brasileiro de Poupança e Empréstimo (SBPE), sendo ambos fundamentais para o crédito habitacional e imobiliário no país. Nesse cenário, o modelo de política habitacional estabelecido pelo BNH se pautou na criação de diferentes propostas operacionais e de financiamento.

Conforme Royer (2009), em 1971, o BNH iniciou uma mudança institucional, sendo finalizada em 1973 com a mudança de autarquia para a formatação de empresa pública. Há uma diversificação nos programas para financiamento de obras urbanas, com empréstimos tomados por estados, municípios e companhias de saneamento. E, a partir daí,

Inicia-se, então, uma segunda fase do BNH com a criação de programas como o CURA (1972), Fundos Regionais para o Desenvolvimento Urbano (1973), Financiamento para Urbanização (1974), Financiamento para Sistemas Ferroviários para Transporte Urbano de Passageiros (1975), Financiamento para Planejamento Urbano (1975), apoio ao Desenvolvimento de Pólos Econômicos (1976) (Royer, 2009, p. 55).

Em 1973, o BNH lançou o Plano Nacional de Habitação Popular (Planhap). Conforme Maricato (1987), esse documento repetiu os objetivos e intenções estabelecidas na criação do $\mathrm{BNH}$ e do SFH, sendo um reconhecimento público por parte do governo de que os programas não atenderam às expectativas.

Dois anos depois, em 1975, foram criados os Programas Complementares, com o desenvolvimento de financiamento de estruturas complementares aos conjuntos habitacionais custeados com recursos do BNH, como os Programas de Financiamento de Equipamento Comunitário de Conjuntos Habitacionais, Financiamento para Urbanização de Conjuntos Habitacionais e Financiamento de Lotes Urbanizados. A partir de 1975, programas destinados à faixa de renda menor, relativos às Cohab, começaram a ter resultados. Esse período é considerado a terceira etapa do BNH, com relevância na Carteira de Operações Sociais no SFH. Assim, em 1976, 
as Cohab "[...] passam a atender também a faixa de renda de 3 a 5 salários-mínimos, e que boa parte dos financiamentos se situam nas faixas de 4 a 5 salários" (Royer, 2009, p. 57).

A quarta e última etapa do BNH diz respeito à criação do Financiamento da Construção ou Melhoria de HIS em 1977, além da renovação do Programa de Lotes Urbanizados em 1978 e do Programa de Erradicação da Sub Habitação, em 1979 (Royer, 2009). ○ BNH entrou em crise no início dos anos 1980, o que levou a sua extinção em 1986, com a transferência da coordenação do SFH para a Caixa Econômica Federal e da regulação para o BCB.

Nessa perspectiva, conforme Coutinho e Nascimento (2006), por meio da variação do indicador estabelecido pela relação entre o crédito habitacional e o PIB, é possível identificar a crise do financiamento habitacional no país, com queda progressiva de 10\% em 1998, para 4\% e $2 \%$ em, respectivamente, 1999 e 2001. Constata-se, portanto, que o período de 1986 a 2003 foi marcado por uma expressiva redução de financiamento habitacional. Nesse período, algumas propostas de financiamento foram estabelecidas, como a criação da Carta de Crédito, projeto que foi parcialmente limitado pelas altas taxas de juros, o que dificultou o acesso das camadas de baixa renda e de setores médios para financiamento de longo prazo (Cardoso; Aragão, 2013).

Durante esse período foram apresentadas algumas propostas, como, por exemplo, em 1990, o Plano de Ação Imediata para a Habitação, cuja proposta consistia em financiar programas de construção de unidades e de lotes urbanizados para famílias com renda de até cinco salários-mínimos. Quatro anos depois, em 1994, foram instituídos os Programas Habitar Brasil e Morar Município, que não se consolidaram (Cardoso, 2003). Durante o primeiro governo do ex-presidente Fernando Henrique Cardoso (1995-1998), extinguiu-se o Ministério do BemEstar Social e se estabeleceu a Secretaria de Política Urbana (Sepurb), responsável pela elaboração e execução da Política Nacional de Habitação.

No segundo governo de Fernando Henrique Cardoso (1999-2002), o Banco Interamericano de Desenvolvimento (BID) financiou os projetos de habitação no país, e, a partir de então, - Programa Habitacional Brasileiro passou a ser denominado Programa Habitar Brasil/BID. "O Programa Habitar-Brasil/BID visava à promoção de intervenções em assentamentos precários, sendo direcionado para famílias com renda de até três salários-mínimos que vivem nesses assentamentos" (Cardoso; Denaldi, 2018, p. 22). Sobre esse cenário, Cardoso (2003, p. 5) destaca:

Excetuando-se os financiamentos internacionais, como o programa Habitar Brasil/ BID, gerenciado pelo governo federal e que redistribui recursos a nível municipal, os empréstimos habitacionais estão hoje limitados à atuação do setor privado, através do Programa de Arrendamento Residencial, ou, aos empréstimos individuais, como o Programa Carta de Crédito. Em ambos os casos, não se atingiu o objetivo principal de atender às populações de menor renda.

Nesse sentido, Pereira, J. (2015) observa que esse movimento estava alinhado ao contexto ideológico/geopolítico internacional, principalmente ao Consenso de Washington, que por intermédio do Banco Mundial prescreveu a reestruturação da assistência social, rechaçando a concessão de auxílios amplos para habitação, infraestrutura ou alimentos em favor de medidas de aplicação de recursos em áreas com altos índices de pauperização, em microcrédito 
para pequenos negócios, sobretudo em programas que demandassem o pagamento de taxas. Além disso, esse banco indicou a necessidade de um trabalho ideológico intensivo no âmbito discursivo, a fim de que as parcelas menos abastadas da população se vissem como empreendedores e o Estado pudesse investir em outras áreas.

Já em 1999, estabeleceu-se o Programa de Arrendamento Residencial (PAR), incluindo o atendimento à população de baixa renda e com a possibilidade de prestações menores. Porém o Programa concentrou seu atendimento na população de renda superior à pretendida. "Do ponto de vista institucional, governos municipais e estaduais participam através do cadastro e seleção prévia dos adquirentes e eventualmente através da doação de terrenos e na redução de exigências urbanísticas, visando redução de custos" (Cardoso, 2003, p. 6).

No final do segundo governo de Fernando Henrique Cardoso, foi criado o Sistema de Financiamento Imobiliário (SFI), com autorização para criar companhias securitizadoras responsáveis pela alienação em garantia de imóveis urbanos e emitir Certificados de Recebíveis Imobiliários (CRI). Vale destacar que a Caixa Econômica Federal e outros bancos públicos, em conjunto com grandes bancos privados nacionais e estrangeiros, são acionistas proprietários da Companhia Brasileira de Securitização (Cibrasec), criada em 1998 (Cardoso; Aragão, 2013).

No início do primeiro governo do ex-presidente Luiz Inácio Lula da Silva (2003-2006) foi criado o Ministério das Cidades. Essa proposta de política urbana implementada pelo governo federal consistiu em uma estrutura que tomava como base para suas ações os problemas sociais que atingiam as populações urbanas e diziam respeito ao território, como a "moradia, o saneamento ambiental (que agrega água, esgoto, drenagem e coleta e destinação de resíduos sólidos) e as questões reunidas sob o tema do transporte da população urbana - mobilidade e trânsito" (Maricato, 2006, p. 215). A formulação do Ministério das Cidades foi ancorada no Projeto Moradia, para o qual o ex-presidente Luiz Inácio Lula da Silva convidou líderes sociais e especialistas visando à formulação de uma proposta em instância federal de políticas urbanas. Nesse viés, o Projeto Moradia estabelece as seguintes medidas:

- Criação do Sistema Nacional de Habitação, formado pelos três entes da Federação (União, estados e municípios), que atuariam de maneira estruturada, sob a coordenação de um novo ministério.

- Gestão Democrática da Política Habitacional e Urbana, a partir da criação dos conselhos nacional, estaduais e municipais de habitação que deveriam definir as diretrizes e realizar a alocação de recursos da política habitacional nos 3 níveis de governo.

- Aprovação do projeto de lei de iniciativa popular de instituição do Fundo Nacional de Habitação, bandeira do movimento de moradia que tramitava desde 1991 no Congresso Nacional.

- Retomada do financiamento habitacional para as camadas médias (SBPE), visando concentrar ao máximo os recursos do FGTS no financiamento para a baixa renda. 
Articulação da política habitacional com a política de controle e recuperação da valorização fundiária e imobiliária (Cardoso; Aragão, 2013, p. 28).

De acordo com Melazzo (2016, p. 94), com a criação do Ministério das Cidades, em 2003, tem início "[...] a retomada da formulação e implementação de uma política habitacional, interrompida pelo fim do BNH, no ano de 1986". Durante o ano de 2003, a Secretaria Nacional de Habitação desenvolveu as bases normativas e institucionais da política de habitação, com uma proposta de estruturação do Sistema Nacional de Habitação. Já no ano de 2005 foi criado o Fundo Nacional de Habitação de Interesse Social (FNHIS), também instituindo o Sistema Nacional de Habitação, com as atribuições distribuídas entre os três entes federados.

Portanto, com a criação do Ministério das Cidades, do Fundo Nacional de Habitação e do Sistema Nacional de Habitação de Interesse Social, em 2005, da Política Nacional de Habitação, em 2009, e do lançamento do MCMV em 2009, de acordo com Melazzo (2016), retomou-se a formulação e implementação de uma política habitacional com interferência direta na produção em massa de habitações.

No estado de São Paulo, a questão habitacional pública foi desenvolvida por meio da Caixa Estadual de Casas para o Povo (Cecap), primeiro órgão destinado a esse assunto, instituída como autarquia vinculada à Secretaria do Trabalho, Indústria e Comércio por meio da Lei n. 483, de 10 de outubro de 1949, durante o primeiro mandato (1947-1951) de Ademar Pereira de Barros como governador do estado, porém a regulamentação ocorreu por meio de decreto em 28 de fevereiro de 1964 (Bonduki, 1998). No entanto, a "fragilidade das finanças públicas estaduais, além da inexistência de um sistema nacional de transferência de recursos vinculados à habitação e a indefinição quanto ao aporte de recursos" fizeram com que a Cecap existisse "apenas nominalmente até 1964" (Royer, 2002, p. 36).

Assim, por meio da Lei n. 905, de 18 de dezembro de 1975, a Cecap foi transformada de autarquia em sociedade por ações, tornando-se a Companhia Estadual de Casas Populares -

mantendo a sigla Cecap. $\bigcirc$ funcionamento da Cecap - como autarquia - foi fundamentado como promotor do sistema SFH/BNH, e, após a alteração para o modelo de sociedade de ações, passou a operar como promotor de sistema e agente financeiro, com recursos do $\mathrm{BNH}$, atuando dentro do Planhap. Em janeiro de 1981, substitui-se o nome da Cecap por Codespaulo, com vistas a atuar no desenvolvimento industrial e urbano de São Paulo (Royer, 2002).

Em seguida, por meio do Decreto n. 21.592, de 3 de novembro de 1983, no governo de André Franco Montoro (1983-1987), foi criada a Secretaria Executiva de Habitação, cujo objetivo era estimular e apoiar os Programas Municipais de Habitação. Em março de 1984, a Codespaulo foi substituída pela Companhia de Desenvolvimento Habitacional do Estado de São Paulo (CDH), por meio de uma administração descentralizada, com mais autonomia dos municípios e abrangendo a população com renda de até três salários-mínimos (Muylaert; Pinheiro, 2000).

Da transformação da CDH surgiu a Companhia de Desenvolvimento Habitacional e Urbano do Estado de São Paulo (CDHU), em junho de 1989, durante o governo de Orestes Quércia (1987-1990). Conforme Royer (2002), a proposta da CDHU era aumentar o número de unidades habitacionais construídas, com uma construção em massa de moradias. Durante os dois primeiros anos do governo Quércia, o setor produtivo da construção civil foi o destaque da 
reestruturação da CDHU, com a meta de 400 mil moradias, consolidando a política de construção em massa de unidades habitacionais na segunda metade desse governo. Esse "novo conceito" "implicou profundas mudanças no setor de obras no Estado, introduzindo os conceitos de "juros zero', de 'áreas comuns', de bônus temporário às familias, por cinco anos" (Royer, 2020, p. 67).

A partir da década de 1990, com a reestruturação da CDHU e a destinação anual de 1\% do Imposto sobre Circulação de Mercadorias e Prestação de Serviços (ICMS) para a habitação, conforme a Lei n. 6.556, de 30 de novembro de 1989, houve um significativo desempenho quantitativo de produção de unidades habitacionais (UH) estadual. No período de 1990 a 1998, "a média da produção anual salta para $24.982 \mathrm{UH} /$ ano, cerca de 5,1 vezes maior que o período anterior. A média anual de investimentos, por sua vez, chega a US $\$ 380,6$, cerca de 7,7 vezes maior que o período anterior" (Denizo, 2007, p. 118). Na década seguinte, mais precisamente com o início do PAC 1, em 2007, entram em cena as políticas de habitação, que são apresentadas a seguir.

\section{O Programa de Aceleração do Crescimento: investimentos em habitação, Urbanização de Assentamentos Precários e Programa Minha Casa Minha Vida}

A UAP e o MCMV são os dois principais programas habitacionais promovidos pelo PAC. O PAC-UAP foi lançado em 2007 e se constitui como um programa de financiamento de obras de urbanização de favelas, desenvolvido entre governos municipais ou estaduais e o governo federal. Por meio dele são financiadas obras de urbanização, requalificação habitacional, regularização fundiária, produção de novas moradias, trabalho social e equipamentos sociais, e ele se estrutura numa linha de atuação que inclui conjuntos habitacionais degradados, loteamentos populares e favelas. Um documento da Secretaria Nacional de Habitação (Brasil, 2010, p. 37) dá as seguintes informações sobre essa iniciativa:

As intervenções físicas abrangem a implantação de infraestrutura básica, incluindo rede elétrica, iluminação pública e saneamento ambiental; a eliminação das situações de risco geotécnico e a redução significativa da frequência das inundações, mediante retaludamentos, estruturas de contenção e intervenção na drenagem fluvial; adequação do sistema viário, de forma a possibilitar o acesso a serviços públicos e de atendimentos emergenciais, melhorando as relações funcionais da área de intervenção com o tecido urbano na qual ela se insere; recuperação ambiental e revegetação de áreas impróprias ao uso habitacional, que venham a ser desocupadas, medidas de desadensamento e reordenamento da ocupação, quando necessárias, apoio à melhoria nas habitações existentes; construção de novas unidades habitacionais e de equipamentos comunitários, entre outras.

Quanto ao desenvolvimento do PAC, ele se estruturou em duas fases (PAC 1 e PAC 2). Durante o PAC 1 (2007-2010), o PAC-UAP pertenceu ao bloco de investimentos relativos à infraestrutura da modalidade social-urbano do PAC. No PAC 2 (2011-2014), a mesma modalidade foi incluída no eixo MCMV (Cardoso; Denaldi, 2018). De acordo com Caldas e Vale (2014), cerca de 10\% dos recursos disponibilizados ao PAC-UAP não foram utilizados. Além disso, durante o 
PAC 1, a média de execução das operações selecionadas foi de 65\%, enquanto no PAC 2 essa execução foi de 5\%, o que indica que o programa perdeu importância na agenda federal.

Vale destacar que, entre 2007 e 2017, foram investidos R\$28,6 bilhões por meio do PACUAP (Quadro 1) e, em 2018, havia 727 empreendimentos em execução no país (Brasil, 2018a).

\section{Quadro 1 - Investimentos do PAC-UAP - 2007-2017}

\begin{tabular}{|l|l|}
\hline Obras concluídas & 1.307 \\
\hline Planos de habitação/projetos de urbanização & 1.575 \\
\hline Municípios contemplados & 1.807 \\
\hline Famílias beneficiadas & $450 \mathrm{mil}$ \\
\hline
\end{tabular}

Fonte: Elaborado pela autora a partir de dados do $6^{\circ}$ Balanço do PAC 2015-2018 (Brasil, 2018a).

Os recursos investidos no PAC-UAP provêm do Fundo de Amparo ao Trabalhador (FAT), do FGTS, do FNHIS e do Orçamento Geral da União (OGU). Conforme Cardoso e Denaldi (2018), há uma concentração de investimentos do PAC-UAP nas regiões Sudeste e Nordeste, mas os investimentos desse Programa abrangem municípios de todas as regiões do país.

No ano de 2009, foi lançado o PMCMV, com a meta inicial de construir um milhão de moradias para famílias com renda de até 10 salários-mínimos e sendo desenvolvido em parceria com municípios, estados e iniciativa privada. Segundo documento oficial, o "[...] objetivo principal do Programa MCMV é criar um ambiente econômico confiável que estimule o desenvolvimento do mercado formal de habitação com subsídios governamentais para famílias de baixa renda e de classe média" (Brasil, 2010, p. 50).

Ainda segundo dados oficiais, no período de 2009 a 2017 foram investidos $\mathrm{R} \$ 398,5$ bilhões por meio do PMCMV, com 5,04 milhões de unidades habitacionais contratadas e 3,6 milhões de unidades habitacionais entregues em todo país, correspondendo a mais de 12 milhões de pessoas beneficiadas (Brasil, 2018a). $\bigcirc$ total de obras entregues e concluídas por região brasileira está na Tabela 1.

Tabela 1 - Total de obras entregues e concluídas pelo PMCMV - 2009-2017

\begin{tabular}{|l|c|c|c|}
\hline \multicolumn{1}{|c|}{ Região } & Obras entregues & Obras concluídas & Total de unidades por região \\
\hline Sudeste & 1.309 .214 & 528.092 & 1.837 .306 \\
\hline Nordeste & 987.031 & 386.964 & 1.373 .995 \\
\hline Sul & 769.947 & 166.823 & 936.770 \\
\hline Centro-Oeste & 425.840 & 150.926 & 576.766 \\
\hline Norte & 191.045 & 122.652 & 313.697 \\
\hline total & $\mathbf{3 . 6 8 3 . 0 7 7}$ & $\mathbf{1 . 3 5 5 . 4 5 7}$ & $\mathbf{5 . 0 3 8 . 5 3 4}$ \\
\hline
\end{tabular}

Fonte: Elaborada pela autora a partir de dados do $6^{\circ}$ Balanço do PAC 2015-2018 (Brasil, 2018a).

Assim, os dados mostram uma concentração dos investimentos por meio das obras entregues e concluídas nas regiões Sudeste e Nordeste. Torna-se importante ressaltar que a capacidade do acesso aos recursos alocados pelo governo federal é de competência dos governos 
locais. Desse modo, por meio dos dados acima demonstrados, evidencia-se o protagonismo do setor público local das regiões Sudeste e Nordeste na distribuição final dos empreendimentos do PMCMV, de maneira que, considerando os níveis por regiões brasileiras, o Sudeste obteve, aproximadamente, 1 milhão e 800 mil unidades (1.837.306), uma cifra nada desprezível.

\section{Desafios científicos e tecnológicos e os meios e métodos para superá-los}

Esta pesquisa compreende a apresentação e a análise dos investimentos em habitação do PAC na promoção da coesão territorial no estado de São Paulo. O conceito de coesão territorial deriva de ações da Comunidade Europeia, sobretudo a partir do Tratado de Lisboa, em 2009, cujo delineamento é baseado no Livro Verde sobre a coesão territorial. ${ }^{1}$ Santinha (2014) indica que o aludido conceito tem como mote tirar partido da diversidade e identidade territoriais, de maneira a fazer um melhor uso dos mecanismos de ordenamento do território. Nessa perspectiva, Chamusca et al. (2020) entendem a coesão territorial como um fenômeno de promoção do equilibrio e da integração - incluindo aspetos de natureza geográfica, socioeconômica e de justiça socioespacial, associados às especificidades de cada espaço e que contribui temporal e espacialmente para a coesão territorial.

Ainda a respeito de sua definição, Abdala e Nunes (2019) assinalam que esse conceito voltou à tônica justamente para fazer referência às possibilidades de ativação de interações colaborativas entre subespaços inscritos em um todo (um território nacional, uma região), capaz de, ao mesmo tempo, promover a articulação e provocar a complementaridade em prol de um projeto de desenvolvimento e integração entre áreas mais desenvolvidas e menos desenvolvidas.

Nesse sentido, de acordo com Ferrão (2011), uma das experiências mais proeminentes das políticas norteadas pelo princípio da coesão territorial é o caso da União Europeia, no qual há um delineamento de políticas de ordenamento do território (aménagement du territoire) que interligam os níveis locais de poder (condados, freguesias, comunas etc.), perpassando as divisões regionais, sobretudo regiões metropolitanas, da escala nacional até a supranacional, o que envolve a deliberação de decisões que se dão no parlamento europeu.

No contexto contemporâneo, o que justifica a recente valorização da coesão territorial é o agravamento da fragmentação territorial . Segundo Pereira, M. (2009, p. 818-819):

A experiência confirma que as intervenções casuísticas tendem a beneficiar os territórios mais ricos (ou mais favorecidos) e os actores com maiores recursos (ou com maior influência) e a comprometer os territórios e as comunidades mais fragilizados. Só uma perspectiva integrada pode contrariar desequilibrios e perseguir o interesse colectivo, razão de ser do envolvimento público. A prevalência da força do mercado e da perspectiva económica, a par do reforço da autonomia dos indivíduos, tende a acentuar os desequilibrios, afectando transversalmente todos os territórios (à escala local, metropolitana, regional, nacional).

1 O Tratado de Lisboa consagra a coesão territorial, a par da coesão econômica e social, entre os objetivos fundamentais da União Europeia (Cf. Comissão das Comunidades Europeias, 2008). 
No caso em tela, a coesão territorial se dá na escala intraurbana, mas também pode ser estendida para a metropolitana, devido à configuração das áreas em análise, cuja maioria pertence a regiões metropolitanas. Nesse sentido, além de garantir o direito à moradia, essas políticas públicas visam coibir a fragmentação territorial em nível urbano e metropolitano. Ademais, vale ressaltar que a escassez de moradia e a aludida fragmentação territorial, em tese, têm profunda ligação com o capitalismo financeiro e oligopolista, o qual tem na terra a extração da renda, demonstrando (via especulação imobiliária) que da:

[...] contradição básica entre fixidez e movimento surge outra camada de dificuldades. Quando as manobras sociais destinadas a facilitar o fluxo de capital (por exemplo, as atividades dos capitalistas comerciais, ou dos financistas, que são ainda mais poderosas) combinam-se com os problemas físicos da fixidez na terra, abre-se espaço para os bens de raiz capturarem uma parte excedente. Essa fração definida do capital extrai rendas e configura investimentos na terra, mesmo que sua impiedosa especulação esteja relacionada à terra, aos recursos naturais ou ao valor da propriedade (Harvey, 2014, p. 78).

Desse modo, com o fito de coibir a fragmentação territorial, criam-se políticas públicas impressas na cidade-região. Nessa ótica, Lencioni (2006) observa que pensar a metrópole, a região metropolitana ou o entorno metropolitano é pensar uma região, tendo em vista que, mesmo quando se fica restrito a uma análise da metrópole, a região aparece indiretamente, pois não se configura mais como uma cidade isolada, mas como uma cidade-região. E uma cidade-região que não se definiu como uma intenção prévia, e sim devido a um processo histórico que desafia a compreensão de sua dinâmica, sobretudo da gestão e do planejamento urbano e regional.

É importante notar ainda que Lencioni (2006) se refere a essa área como uma cidade-região, tendo como centro primaz a metrópole paulista, que congrega uma próspera área econômica, tendo lado a lado, como contrapartida, um altíssimo contingente de pessoas que vivem em condições de extrema pobreza (Figura 1). Para a autora, esse processo de constituição de uma cidade-região rompe os limites administrativos/formais e é estreitamente vinculado ao processo de desconcentração industrial no estado de São Paulo.

No que concerne à eficiência dessa política pública, pode-se verificar a distribuição dos investimentos do PAC-UAP nos municípios da RMSP e da RAC, o que leva a constatar uma concentração desses investimentos nos municípios da RMSP e em seu entorno (Tabela 2).

Fica evidente, portanto, que os assentamentos precários que passaram por regularização fundiária encontram-se, sobretudo, na densa área da cidade-região (Lencioni, 2006). Vale mencionar também o fato de que, a despeito do desenvolvimento econômico e industrial, a região abriga parcela expressiva de coletivos pauperizados, uma face perversa do desenvolvimento geograficamente desigual (Soja, 1993) engendrado pelo capitalismo.

Trazer à baila esse debate implica sobretudo discutir o papel do Estado na diminuição dos índices de desigualdade, da pobreza e da garantia do direito civil à moradia. Nessa perspectiva, Scott et al. (2001) mostram que esse caráter perverso resulta também do processo de formação das cidades-regiões, inclusive São Paulo, já que a reorganização socioespacial teve incontáveis 
consequências negativas, e, como essas cidades se expandiram para fora, sua população se diversificou bastante, acarretando um conjunto complexo de disfunções espaciais em empregos, moradias e equipamentos de transporte, os quais, por sua vez, tiveram muitos impactos ambientais.

Tabela 2 - Investimentos PAC/UAP (em R\$ milhares) no estado de São Paulo, na RMSP e na RAC - 2007-2010

\begin{tabular}{|c|c|c|c|c|c|}
\hline Investimento PAC/UAP & Estado de São Paulo & RMSP & $\mathbf{\%}$ & RAC & \% \\
\hline 2007 & $3.319 .665,41$ & $2.241 .019,55$ & 67,51 & $62.138,13$ & 1,88 \\
\hline 2008 & $457.039,10$ & $131.521,51$ & 28,78 & $20.281,07$ & 4,44 \\
\hline 2009 & $613.270,29$ & $564.871,12$ & 63,35 & $48.203,43$ & 7,86 \\
\hline 2010 & $891.653,37$ & $684.831,7$ & 76,80 & $85.857,76$ & 9,63 \\
\hline total & $\mathbf{5 . 2 8 1 . 6 2 8 , 1 7}$ & $\mathbf{3 . 6 2 2 . 2 4 3 , 8 8}$ & $\mathbf{6 8 , 5 8}$ & $\mathbf{2 1 6 . 4 8 0 , 3 9}$ & $\mathbf{4 , 1 0}$ \\
\hline
\end{tabular}

Fonte: Elaborado pela autora a partir de dados do $6^{\circ}$ Balanço do PAC 2015-2018 - Cartilha Regional São Paulo (Brasil, 2018b).

Assim, ainda segundo Scott et al. (2001), de um lado, esse estado de coisas agravou os problemas dos pobres do centro urbano, porque os melhores empregos somem para as edge cities, o estoque habitacional se torna escasso e superpovoado, e aumenta o número de sem-teto. Por outro lado, a expansão acelerada para fora da franja urbana cria, muitas vezes, áreas periféricas isoladas, onde as famílias, atraídas por moradia barata, fixam residência tão longe de seu lugar de trabalho que o tempo de transporte se torna muito demorado todos os dias (Scott et al., 2001, p. 15).

O mapa a seguir (Figura 1) mostra como os recursos do PAC-UAP foram investidos nos municípios durante o período de 2007 a 2012:

\section{Figura 1 - Mapa da distribuição dos recursos do PAC-UAP investidos nos municípios da RMSP e RAC - 2007-2010}
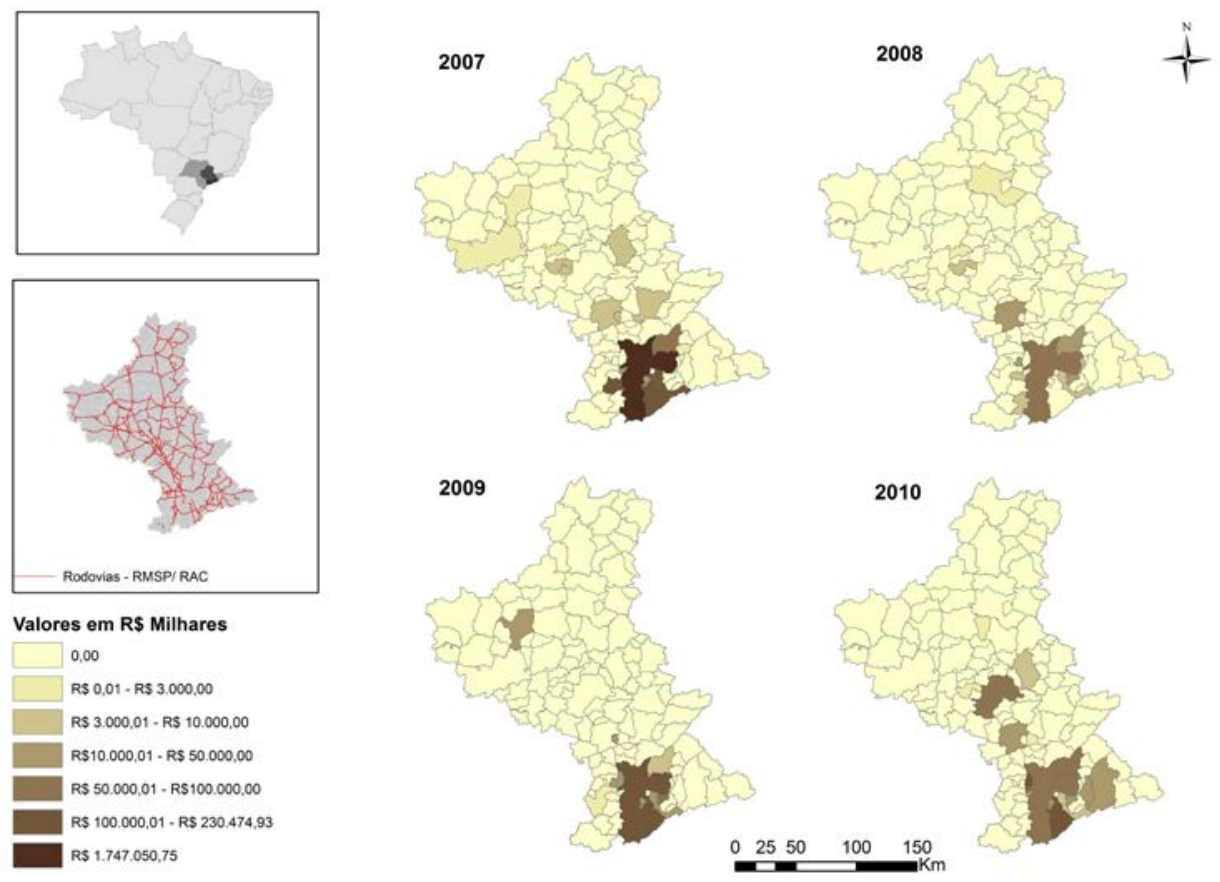

2010

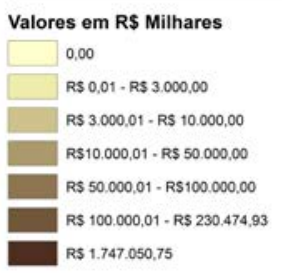

Fonte: Elaborado pela autora a partir de dados do $6^{\circ}$ Balanço do PAC 2015-2018 - Cartilha Regional São Paulo (Brasil, 2018b). 
Sobre o mapeamento da cidade-região em tela, Lencioni (2011) explica que ela tem grande extensão territorial, com cerca de 200 quilômetros de raio a partir do seu centro (São Paulo), os limites entre os municípios são diluídos graças à conurbação, ou muito tênues, num cenário de paisagens em que não é possível distinguir claramente o intraurbano e o interurbano e menos ainda o rural e o urbano, que tendem a se interpenetrar. Destarte, as áreas construídas - quer para estabelecimentos fabris, quer para comércio ou habitação - contrastam com o intervalo da descontinuidade do espaço construído.

Quanto à distribuição das obras concluídas do PMCMV, no estado de São Paulo, foram contemplados 589 municípios, representando 91,3\% do total, sendo organizados por região administrativa (Tabela 3). Ao mesmo tempo, com uma concentração nas grandes cidades pertencentes à RMSP e à RAC, com destaque para os municípios de São Paulo, com 134.948, e de Campinas, com 68.915 obras concluídas. Tais resultados reiteram a predileção pela construção civil das supracritadas políticas públicas que se inserem na cidade-região paulista, como ilustrado na Tabela 3.

\section{Tabela 3 - Total de obras concluídas do PMCMV por região paulista - 2011-2014}

\begin{tabular}{|l|c|c|}
\hline Região & Total de obras (\%) & Total de municípios (\%) \\
\hline Região Metropolitana de São Paulo & 27,40 & 87,5 \\
\hline Região Administrativa de Campinas & 21,70 & 95,6 \\
\hline Região Administrativa de São José dos Campos & 7,20 & 61,5 \\
\hline Região Administrativa de Sorocaba & 7,00 & 89,4 \\
\hline Região Administrativa de São José do Rio Preto & 6,50 & 94,8 \\
\hline Região Administrativa de Ribeirão Preto & 5,00 & 100,0 \\
\hline Região Administrativa de Bauru & 4,90 & 94,9 \\
\hline Região Administrativa Central & 4,60 & 100 \\
\hline Região Administrativa de Marilia & 3,30 & 88,2 \\
\hline Região Administrativa de Santos & 2,70 & 100,0 \\
\hline Região Administrativa de Franca & 2,70 & 95,7 \\
\hline Região Administrativa de Araçatuba & 2,30 & 86,0 \\
\hline Região Administrativa de Presidente Prudente & 2,20 & 94,3 \\
\hline Região Administrativa de Barretos & 1,70 & 100,0 \\
\hline Região Administrativa de Itapeva & 0,70 & 87,5 \\
\hline Região Administrativa de Registro & 0,10 & 85,7 \\
\hline total & $\mathbf{1 0 0}$ & $\mathbf{9 1 , 3}$ \\
\hline
\end{tabular}

Fonte: Elaborado pela autora a partir de indicadores do MCMV (Brasil, 2018c).

Na Figura 2, vê-se a dimensão cartográfica dos dados da Tabela 3, sobre a distribuição das obras concluídas do PMCMV nos municípios do estado de São Paulo. 


\section{Figura 2 - Mapa da distribuição das obras concluídas do PMCMV dos municípios da RMSP e RAC - 2011-2014}
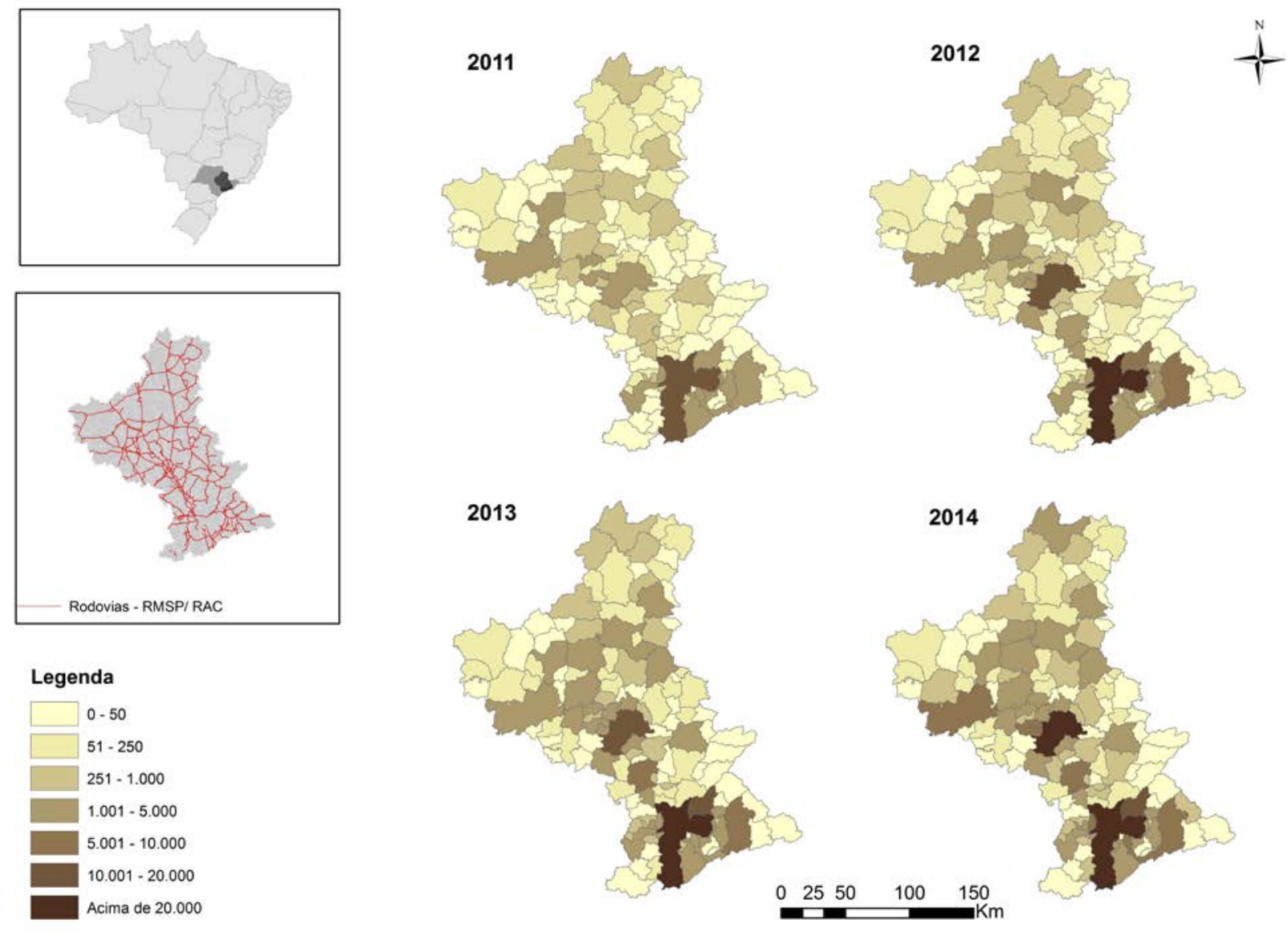

2014

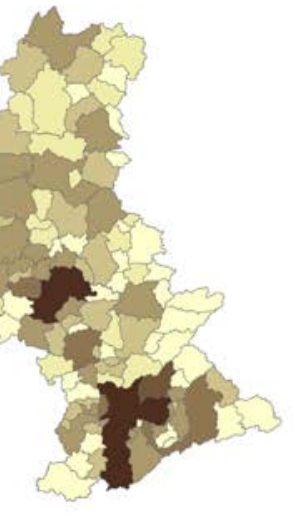

Fonte: Elaborado pela autora a partir de dados dos indicadores do MCMV (Brasil, 2018c).

Considerando os dados apresentados nesse mapa, constata-se que os investimentos do PMCMV contemplaram municípios de diferentes regiões paulistas. Nessa lógica, observando essas informações e relacionando-as à situação econômica do país, Brandão (2013a) adverte que a realidade da competitividade econômica e do emprego no Brasil está restrita à capacidade de internalizar os efeitos multiplicadores da renda e do emprego de modo a desperdiçar o potencial de tornar efetivos (e mais duradouros) os efeitos intersetoriais do gasto agregado, sujeitando a dinâmica territorial a determinações transescalares, dificultando iniciativas de coesão territorial e promovendo concentração espacial em localidades que a iniciativa privada considera atrativas.

Nesse sentido, de acordo com Paulani (2016) e Sanfelici (2013), as organizações envolvidas em projetos de infraestrutura não se vinculam apenas à construção civil, mas também englobam corporações financeiras, não financeiras (industriais, comerciais e agropecuárias) e prestadoras de serviços especializados, como as consultorias. Assim, empresas de grande e médio porte, crescentemente controladas por agentes internacionais, tornam-se portadoras de uma progressiva desnacionalização, levando à perda de comando das decisões de investimento em infraestrutura no país.

Por isso, é preciso combater essa desnacionalização se se pretende promover um desenvolvimento que respeite a justiça fundiária ou, no mínimo, atenue a profunda injustiça brasileira 
nessa área e queira promover a coesão territorial no estado de São Paulo e no Brasil. Portanto, é necessário acompanhar seriamente o delineamento das políticas públicas de habitação com uma análise de seus resultados, a fim que o direito básico à moradia seja de fato garantido a um maior número de pessoas.

\section{Considerações finais}

Com a criação dos Estados modernos, sobretudo com o direito civil moderno, criou-se (ao menos no plano discursivo) um conjunto de direitos difusos e coletivos, entre os quais consta o direito à moradia. Desde então, tem havido inúmeras experiências nacionais e internacionais para a efetivação desse direito. Entretanto, e principalmente nos países de economia periférica, esse direito ainda está muito longe de ser consumado, e, no caso brasileiro, o deficit habitacional permanece relativamente grande. Em razão disso, este artigo analisa como se viabilizaram as políticas públicas do PAC-MCMV e do PAC-UAP no maior estado da federação (São Paulo) e quais foram os resultados preliminares.

Diante dos dados levantados e das considerações desenvolvidas, pode-se concluir que o PAC-MCMV apresentou uma dispersão espacial por todo o estado, abrangendo 589 municípios, mas concentrando-se nas áreas próximas a São Paulo e a Campinas. Além disso, os números sugerem que houve uma distribuição mais homogênea das obras do PAC-MCMV pelo estado de São Paulo, a despeito da grande concentração das obras do PAC-UAP na cidade-região, com ênfase nas metrópoles de São Paulo e Campinas. No tocante ao PAC-UAP, pode-se perceber a concentração espacial na cidade-região paulista, áreas que abrangem sumariamente São Paulo e Campinas. Com base nesses resultados, recomenda-se que estudos futuros focalizem os desdobramentos dessas políticas públicas, verificando se elas atingirão os objetivos predefinidos. E, embora não faça parte do escopo deste artigo, sugere-se ainda que estudos posteriores avaliem a eficiência das políticas públicas, tendo em vista que elas são realizadas com vultosos investimentos - dinheiro público advindo do contribuinte.

\section{Referências}

ABDALA, B.; NUNES, J. Desenvolvimento, governança e coesão territorial: a atualidade para o debate. In: ENCONTRO NACIONAL DA ASSOCIAÇÃO NACIONAL DE PÓSGRADUAÇÃO E PESQUISA EM PLANEJAMENTO URBANO E REGIONAL, 18., 2019, Natal. Anais... Natal, 2019. p. 1-25. Disponível em: http://anpur.org.br/xviiienanpur/anaisadmin/capapdf.php?reqid=1500. Acesso em: 30 set. 2019.

ABERS, R. N. Conflitos, mobilizações e participação institucionalizada: a relação entre a sociedade civil e a construção de grandes obras de infraestrutura. Rio de Janeiro: Ipea, 2016.

ABREU, C. R.; CÂMARA, L. M. O orçamento público como instrumento de ação governamental: uma análise de suas redefinições no contexto da formulação de políticas públicas de infraestrutura. Revista de Administração Pública, Rio de Janeiro, v. 49, n. 1, p. 73-90, jan./fev. 2015. doi: https://doi.org/10.1590/0034-76121776. 
BARBOSA, N.; SOUZA, J. A. P. A inflexão do governo Lula: política econômica, crescimento e distribuição de renda. In: SADER, A.; GARCIA, M. Brasil, entre o passado e o futuro. São Paulo: Fundação Perseu Abramo/Boitempo, 2010. p. 1-40.

BONDUKI, N. Origens da habitação social no Brasil. São Paulo: Estação Liberdade, 1998. BRANDÃO, C. A. Prefácio. In: STEINBERGER, M. (org.). Território, Estado e políticas públicas espaciais. Brasilia: Ler Editora, 2013a. p. 5-7.

BRANDÃO, C. A. Pacto federativo, reescalonamento do Estado e desafios para a integração e coesão regionais e para legitimar políticas de desenvolvimento regional no Brasil. In: BRANDÃO, C. A.; SIQUEIRA, H. (org.). Pacto federativo, integração nacional e desenvolvimento regional. São Paulo: FPA, 2013b. p. 163-174.

BRASIL. Comitê Gestor do PAC. $\mathbf{6}^{\circ}$ Balanço do PAC - 2015-2018. 2018a. Disponível em: http://pac.gov.br/pub/up/relatorio/1lfbe9b2f7cbecb3ec5clf9f67b5f3be.pdf. Acesso em: 23 maio 2019.

BRASIL. Comitê Gestor do PAC. $6^{\circ}$ Balanço do PAC - 2015-2018: Cartilha Regional São Paulo. 2018b. Disponível em: http://pac.gov.br/sobre-o-pac/publicacoesnacionais. Acesso em: 23 maio 2019.

BRASIL. Comitê Gestor do PAC. Indicadores sobre Minha Casa Minha Vida. 2018c.

Disponível em: http://dados.gov.br/dataset/minha-casa-minha-vida. Acesso em: 23 maio 2019.

BRASIL. Ministério das Cidades. Secretaria Nacional de Habitação. Avanços e desafios: política nacional de habitação. Brasilia, 2010.

CALDAS, M. F; VALE, M. L. O programa de aceleração do crescimento e as obras de infraestrutura urbana - avanços e desafios. In: SEMINÁRIO NACIONAL SOBRE URBANIZAÇÃO DE FAVELAS, 1., 2014, São Bernardo do Campo: UFABC. Anais... São Bernardo do Campo, 2014. p. 1-19.

CARDOSO, A. L. Política habitacional no Brasil: balanço e perspectivas. Proposta - Revista Trimestral de Debate da Fase, Rio de Janeiro, v. 30, n. 95, p. 6-17, 2003. Disponível em: https://fase.org.br/wp-content/uploads/2016/07/Proposta-Revista-Trimestral-deDebate-da-Fase-n\%C2\%BA-95-2003-02.pdf. Acesso em: 14 jun. 2021

CARDOSO, A. L.; ARAGÃO, T. A. Do fim do BNH ao Programa Minha Casa Minha Vida: 25 anos da política habitacional no Brasil. In: CARDOSO, A. L. (org.). O programa Minha Casa Minha Vida e seus efeitos territoriais. Rio de Janeiro: Letra Capital, 2013. p. 17- 65.

CARDOSO, A. L.; DENALDI, R. Urbanização de favelas no Brasil: um balanço preliminar do PAC. Rio de Janeiro: Letra Capital, 2018.

CARDOSO JÚNIOR, J. C.; NAVARRO, C. A. O planejamento governamental no Brasil e a experiência recente (2007 a 2014) do Programa de Aceleração do Crescimento (PAC). Brasilia/Rio de Janeiro: Ipea, 2016. 
CHAMUSCA, P.; MARQUES, J. L.; PIRES, S.; TELES, F. Coesão territorial: analisando o conceito, as dimensões e as escalas. In: CONFERÊNCIA DE PLANEAMENTO REGIONAL E URBANO, 5., 2020, Aveiro. Anais... Aveiro, PT: UA Editora, 2020. p. 15-16.

COMISSÃO DAS COMUNIDADES EUROPEIAS. Livro verde sobre a coesão territorial européia: tirar partido da diversidade territorial. Bruxelas: EU, 2008. Disponível em: https://ec.europa.eu/regional_policy/archive/consultation/terco/paper_terco_ pt.pdf. Acesso em: 6 maio 2020.

COUTINHO, L. M.; NASCIMENTO, M. M. Crédito habitacional acelera o investimento habitacional no país. In: TORRES FILHO, E. T.; PUGA, F. P.; FERREIRA, F. M. R. (org.). Visão do desenvolvimento. Rio de Janeiro: BNDES, 2006. p. 1-7.

$\mathrm{DENIZO}, \mathrm{V}$. Os produtos da política estadual de habitação na Região Metropolitana de São Paulo: elementos para análise de uma política metropolitana de habitação. Tese (Doutorado em Arquitetura e Urbanismo) - Faculdade de Arquitetura e Urbanismo, Universidade de São Paulo, São Paulo, 2007.

ESRI Inc. ArcMap, Versão 10.5.1. Redlands, CA, 2016.

FERR ÃO, J. O ordenamento do território como política pública. Lisboa: Fundação Calouste Gulbenkian, 2011.

FONSECA, I. F; REZENDE, R. R.; OLIVEIRA, M. S.; PEREIRA, A. K. Audiências públicas: fatores que influenciam seu potencial de efetividade no âmbito do Poder Executivo Federal. Revista do Serviço Público, Brasília, v. 64, n. 1, p. 7-29, jan./mar. 2013. doi: https://doi.org/10.21874/rsp.v64il.113.

HARVEY, D. 17 contradições e o fim do capitalismo. Trad. Rubens Enderle. São Paulo: Boitempo, 2014.

LENCIONI, S. A metamorfose de São Paulo: o anúncio de um novo mundo de aglomerações difusas. Revista Paranaense de Desenvolvimento, Curitiba, n. 120, p. 133-148, 2011.

LENCIONI, S. Da cidade a sua região à cidade-região. In: SILVA, J. B.; LIMA, L. C.; ELIAS, D. (org.). Panorama da geografia brasileira. São Paulo: Annablume, 2006. p. 65-76.

MARICATO, E. O Ministério das Cidades e a política nacional de desenvolvimento urbano. In: Políticas sociais: acompanhamento e análise. Brasília: Ipea, 2006. p. 211-220. Disponível em: https://www.ipea.gov.br/portal/images/stories/PDFs/politicas_sociais/ bps_12_completo.pdf. Acesso em: 14 jun. 2021.

MARICATO, E. Política habitacional no regime militar: do milagre brasileiro à crise econômica. Petrópolis, RJ: Vozes, 1987.

MELAZZO, E. S. O Programa Minha Casa Minha Vida no estado do Rio Grande do Norte: cinco conclusões possíveis e cinco questões para a continuidade da investigação. Formação, Presidente Prudente, n. 23, v. 1, p. 92-111, 2016. doi: https://doi.org/10.33081/formacao. vli23.359. 
MUYLAERT, E.; PINHEIRO, P. S. Franco Motoro: democrata e estadista. Novos Estudos Cebrap, São Paulo, n. 56, p. 3-8, mar. 2000.

PAULANI, L. M. Acumulação e rentismo: resgatando a teoria da renda de Marx para pensar o capitalismo contemporâneo. Revista de Economia Política, São Paulo, v. 36, n. 3, p. 514-535, jul./set. 2016. doi: https://doi.org/10.1590/0101-31572016v36n03a04.

PEREIRA, J. M. M. Continuidade, ruptura ou reciclagem? Uma análise do programa político do Banco Mundial após o Consenso de Washington. Dados, Rio de Janeiro, v. 58, n. 2, 2015. doi: https://doi.org/10.1590/00115258201550.

PEREIRA, M. Cultura de planeamento e governação: contributos para a coesão territorial. In: CONGRESSO DE DESENVOLVIMENTO REGIONAL DE CABO VERDE, 15. Cabo Verde, 2009. Anais... Cabo Verde: ADPR, 2009. p. 816-838.

ROSSI, P. L. Taxa de câmbio no Brasil: dinâmicas da arbitragem e da especulação. Tese (Doutorado em Ciências Econômicas) - Instituto de Economia, Universidade Estadual de Campinas, Campinas, 2012.

ROYER, L. O. Financeirização da política habitacional: limites e perspectivas. Tese (Doutorado em Arquitetura e Urbanismo) - Faculdade de Arquitetura e Urbanismo, Universidade de São Paulo, São Paulo, 2009.

ROYER, L. O. Política habitacional no estado de São Paulo: estudo sobre a Companhia de Desenvolvimento Habitacional e Urbano do Estado de São Paulo, CDHU. Dissertação (Mestrado em Arquitetura e Urbanismo) - Faculdade de Arquitetura e Urbanismo, Universidade de São Paulo, São Paulo, 2002.

SANFELICI, D. Financeirização e a produção do espaço urbano no Brasil: uma contribuição ao debate. Eure, Santiago, CL, v. 39, n. 118, p. 27-46, set. 2013. doi: http://dx.doi. org/10.4067/S0250-71612013000300002.

SANTINHA, G. $\bigcirc$ princípio de coesão territorial enquanto novo paradigma de desenvolvimento na formulação de políticas públicas: (re)construindo ideias dominantes. Eure, Santiago, CL, v. 40, n. 119, p. 75-97, 2014. doi: http://dx.doi.org/10.4067/ S0250-71612014000100004.

SCOTT, A. J.; AGNEW, J.; SOJA, E. W.; STORPER, M. Cidades-regiões globais. Espaço E Debates, São Paulo, v. 17, n. 41, p. 7-25, 2001.

SOJA, E. Geografias pós-modernas: a reafirmação do espaço na teoria social crítica. Rio de Janeiro: Jorge Zahar, 1993.

\section{Contribuição dos autores:}

Angélica Vieira de Souza-Lopes: fez o levantamento e a tabulação dos dados, o mapeamento e a investigação sobre as políticas habitacionais. 
Thiago Bueno Saab: discutiu conceitos teóricos como coesão territorial e cidade-região, além de proposições sobre as contradições do modo capitalista de produção.

Recebido em: 9 set. 2020 Aprovado em: 7 jun. 2021 